\title{
Increased risk of pulmonary
} and extrapulmonary tuberculosis infection in patients with polycystic kidney disease: a nationwide population-based study with propensity score-matching analysis

Ting-Fang Chiu ${ }^{1,2,3}$, Tung-Min Yu ${ }^{4,5^{*}+}$, Chih-Wei Chiu ${ }^{4,11}$, Brian K. Lee ${ }^{9}$, Tsuo-Hung Lan ${ }^{6,7,8}$, Chi-Yuan Li ${ }^{4,10}$, Mei-Chen Lin ${ }^{4}$ and Chia-Hung Kao ${ }^{4,12,13,14^{*}+}$

\begin{abstract}
Background: Polycystic kidney disease (PKD) is a common renal disorder affecting approximately 1 in 1000 live births. Tuberculosis (TB) is an infectious disease worldwide. This study investigated the risk of TB infection in patients with PKD.

Methods: A nationwide population-based cohort study was performed using Taiwan's National Health Insurance Research Database. We used patients' hospitalization files for the entire analysis during 2000-2012. As per diagnosis, we divided patients into PKD and non-PKD cohorts and the major outcome was TB infection.

Results: A total of 13,540 participants with 6770 patients in each cohort were enrolled. The PKD cohort had a higher risk of TB infection than did the non-PKD cohort after adjusting for age, sex, and comorbidities (adjusted hazard ratio $(\mathrm{aHR})=1.91,95 \%$ confidence interval $[\mathrm{Cl}]=1.51-2.43)$. When classifying by sites of pulmonary TB (PTB) and extrapulmonary TB (EPTB), the PKD cohort demonstrated a significantly higher risk of EPTB ( $\mathrm{aHR}=2.44,95 \% \mathrm{Cl}=1.46-4.08)$ as well as a risk of PTB ( $\mathrm{aHR}=1.69,95 \% \mathrm{Cl}=1.29-2.22)$. When stratified by the presence or absence of a comorbidity, high TB infection risk was noted in the PKD patients without any comorbidity $(H R=2.69,95 \% \mathrm{Cl}=1.69-4.30)$.
\end{abstract}

Conclusions: Taken together, our findings suggest that PKD is associated with a 1.91-fold increased risk of TB infection. Medical professionls should maintain a high index of suspicion in daily practice for patients with PKD, particularly those with EPTB infection.

Keywords: Polycystic kidney disease, Mycobacterium tuberculosis, Lymphopenia

*Correspondence: yu5523@gmail.com; d10040@mail.cmuh.org.tw; dr.kaochiahung@gmail.com

${ }^{\dagger}$ Tung-Min Yu and Chia-Hung Kao equally contributed

${ }^{4}$ Graduate Institute of Biomedical Sciences and School of Medicine, College of Medicine, China Medical University, No. 2, Yuh-Der Road, Taichung 404, Taiwan

Full list of author information is available at the end of the article

\begin{abstract}
Background
Polycystic kidney disease (PKD), the most common form of renal disorders, is characterized by gradually enlarged kidneys filled with growing cysts. Its incidence was estimated at 1 in every $400-1000$ live births by a study published in 1957 [1]. Recent studies from the United States and Europe have reported that the prevalence of PKD ranges from 3.3 to 4.6 per 10,000 [2-5]
\end{abstract}

(c) The Author(s) 2021. This article is licensed under a Creative Commons Attribution 4.0 International License, which permits use, sharing, adaptation, distribution and reproduction in any medium or format, as long as you give appropriate credit to the original author(s) and the source, provide a link to the Creative Commons licence, and indicate if changes were made. The images or other third party material in this article are included in the article's Creative Commons licence, unless indicated otherwise in a credit line to the material. If material is not included in the article's Creative Commons licence and your intended use is not permitted by statutory regulation or exceeds the permitted use, you will need to obtain permission directly from the copyright holder. To view a copy of this licence, visit http://creativeco mmons.org/licenses/by/4.0/. The Creative Commons Public Domain Dedication waiver (http://creativecommons.org/publicdomain/ zero/1.0/) applies to the data made available in this article, unless otherwise stated in a credit line to the data. 
and that it is the fourth leading cause of end-stage renal disease (ESRD) after diabetes mellitus, hypertension, and glomerulonephritis in the United States [2].

PKD is the most common congenital renal disease caused by a mutation in the PKD1 gene on chromosome 16 and $P K D 2$ gene on chromosome 4 accounting for $85 \%$ and $15 \%$ of the disease, respectively [6]. The monogenetic mutation leads to significant insufficiency of the phenotype protein polycystin (PC)1 or PC2. Patients with $P K D 1$ mutations exhibited a more severe phenotype than did those with PKD2 mutations, and those with $P K D 1$ mutations present with earlier onset of clinical problems and ESRD [7]. The renal manifestations of PKD include urine-concentrating defect, hematuria, nephrolithiasis, urinary tract infection, flank or abdominal pain, hypertension, proteinuria, chronic kidney disease, and ESRD [8-10]. Approximately $5 \%$ of the total number of ESRD cases are caused by PKD in the United States [11, 12].

Patients with PKD were suggested to exhibit various extrarenal manifestations resulting from the gene mutations of $\mathrm{PC} 1$ or PC2. The predominant abnormalities are cerebral aneurysms, hepatic and pancreatic cysts, cardiac valve disease, colonic diverticula, abdominal wall and inguinal hernia, seminal vesicle cysts, bronchiectasis, and an increased risk of cancer including renal cell carcinoma $[8,13-16]$.

Increasing evidence suggests that PKD is associated with underlying immune dysregulation. Mutations of $\mathrm{PC} 1$ and $\mathrm{PC} 2$ are observed to be associated with decreased proliferation of immortalized lymphoblastoid cells in PKD. PKD is clinically characterized by severe lymphopenia, especially with low blood $\mathrm{CD} 8^{+} \mathrm{T}$ and $\mathrm{B}$ lymphocytes, irrespective of kidney function [17].

Tuberculosis (TB) is an emerging infectious disease and is currently prevalent in more than one-third of the world's population [18]. Host resistance to infection from Mycobacterium tuberculosis is significantly mediated by cellular immunity. Among various cells with adaptive immunity, $\mathrm{T}$ cells have been considered to play a crucial role in preventing TB infection, and animal studies have proved that $\mathrm{CD} 4+\mathrm{T}$ cells were involved in providing resistance against M. tuberculosis [19]. For example, the increased risk of TB in HIV infection with depleted $\mathrm{CD} 4+\mathrm{T}$ cells also suggests the importance of these cells in protection against TB.

A study reported that patients with PKD displayed lymphopenia including low counts of $\mathrm{T}$ and $\mathrm{B}$ cells [17]. In this study, we hypothesized that patients with PKD are more prone to developing TB infection. However, the risk of TB infection in patients with PKD remains unknown. Therefore, this study examined the risk of TB infection in patients with PKD.

\section{Method}

Data source

In 1995, Taiwan started a single-payer National Health Insurance (NHI) program, and nearly $99.9 \%$ of Taiwan's citizens have been enrolled in this program. The National Health Insurance Research Database (NHIRD) includes the inpatient, outpatient, medical treatment, medication, and other medical service records of patients enrolled in the NHI program. To protect patients' privacy, their identification numbers are encrypted before releasing the database. In this study, we used hospitalization files for the entire analysis. All patients had at least once hospitalization record with diagnoses defined according to the International Classification of Diseases, Ninth Revision, Clinical Modification (ICD-9-CM) codes. The Research Ethics Committee of China Medical University and Hospital in Taiwan approved the study (CMUH104-REC2-115-AR4).

\section{Study population}

We defined two cohorts in this study, namely the PKD and non-PKD cohorts. Patients with PKD were selected with diagnoses of ICD-9-CM codes 753.12 and 753.13 and at least one hospitalization during 2000-2012. The index date was set as the date of PKD diagnosis. The nonPKD group comprised patients without any diagnosis of PKD and were propensity score-matched with PKD cases by age, sex, index year, and comorbidities. The index year of the control group was randomly assigned according to the index date distribution of PKD cases before matching (Fig. 1).

Comorbidities included in this study were alcoholrelated diseases (ICD-9-CM codes 291, 303, 305.00, 305.01, 305.02, 305.03, 571.0-571.3, 790.3 and V11.3), chronic kidney disease (ICD-9-CM codes 580589), chronic liver disease (ICD-9-CM codes 571.5, 571.6,V02.61，070.20，070.22，070.30，070.32,V02.62, $070.41, \quad 070.44, \quad 070.51,070.54,571.40,571.41, \quad 571.49$, 571.8, and 571.9), chronic obstructive pulmonary disease (COPD; ICD-9-CM codes 491, 492, and 496), diabetes mellitus (ICD-9-CM code 250), bacterial and viral infections, pneumoconiosis (ICD-9-CM codes 50 and A326), hypertension (ICD-9-CM codes 401-405), and hyperlipidemia (ICD-9-CM code 272).

The primary outcome of interest was the diagnosis of TB infection (ICD-9-CM codes 01 and A02), and the exclusion criterion was a diagnosis of TB infection before the index date of diagnosis with PKD. All patients were followed up from the index date until the diagnosis of TB infection, withdrawal from the NHIRD, death, or December 31, 2013. 


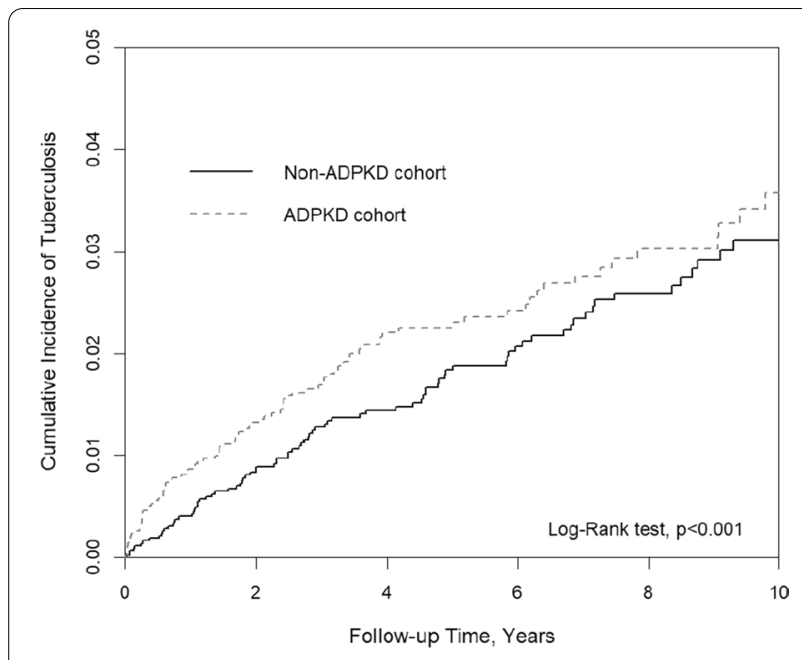

Fig. 1 Cumulative incidence of Mycobacterium tuberculosis infection in the PKD and non-PKD cohorts, which reached a statistical significance $(p<0.001)$

\section{Statistical analysis}

Categorical and continuous variables are presented using numbers (percentages) and means (standard deviations), respectively. The difference in each grouped variable between the two cohorts was tested using the chi-square test; the mean age was assessed using Student's $t$-test. The incidence rate was calculated as the number of patients newly diagnosed with TB divided by the following period (per 10,000 personyears). We used the Kaplan-Meier analysis to calculate the cumulative incidence of $\mathrm{TB}$ and the log-rank test to evaluate the difference in survival curves between the two cohorts. The risk of TB in the PKD and non-PKD cohorts was tested using the Cox proportional hazards model for estimation and comparison demonstrated by hazard ratios (HRs), adjusted HRs (aHRs; adjusted for demographic factors and comorbidities), and 95\% confidence intervals (95\% CIs). All statistical analyses were performed using SAS statistical software, version 9.4 (SAS Institute Inc., Cary, NC). The cumulative

Table 1 Demographic characteristics and comorbidities of patients with newly diagnosed PKD in Taiwan during 2000-2012

\begin{tabular}{|c|c|c|c|c|}
\hline \multirow[t]{4}{*}{ Variable } & \multicolumn{3}{|l|}{ PKD } & \multirow[t]{4}{*}{$p$-value } \\
\hline & Total & No & Yes & \\
\hline & $N=13,540$ & $n=6770$ & $n=6770$ & \\
\hline & $\mathrm{n}$ & $\mathrm{n}(\%) /$ mean \pm SD & n (\%) / mean \pm SD & \\
\hline \multicolumn{4}{|l|}{ Gender } & \multirow[t]{3}{*}{0.81} \\
\hline Female & 5660 & $2823(41.7)$ & 2837 (41.9) & \\
\hline Male & 7880 & $3947(58.3)$ & $3933(58.1)$ & \\
\hline \multicolumn{4}{|l|}{ Age at baseline } & \multirow[t]{5}{*}{0.99} \\
\hline $20-34$ & 1164 & $583(8.6)$ & $581(8.6)$ & \\
\hline $35-49$ & 3168 & $1580(23.3)$ & $1588(23.5)$ & \\
\hline $50-64$ & 3903 & $1945(28.7)$ & $1958(28.9)$ & \\
\hline$>65$ & 5305 & $2662(39.3)$ & $2643(39)$ & \\
\hline Age, mean(SD) & & $59.1(16.8)$ & $59.1(16.8)$ & 0.99 \\
\hline \multicolumn{5}{|l|}{ Comorbidity } \\
\hline Hypertension & 4509 & $2266(33.5)$ & $2243(33.1)$ & 0.67 \\
\hline Hyperlipidemia & 742 & $381(5.6)$ & $361(5.3)$ & 0.45 \\
\hline Alcohol related disease & 161 & $87(1.3)$ & $74(1.1)$ & 0.30 \\
\hline Chronic kidney disease & 2853 & $1427(21.1)$ & $1426(21.1)$ & 0.98 \\
\hline ESRD & 1437 & $714(10.5)$ & $723(10.7)$ & 0.80 \\
\hline Chronic liver disease & 885 & $454(6.7)$ & $431(6.4)$ & 0.42 \\
\hline COPD & 801 & $396(5.8)$ & $405(6)$ & 0.74 \\
\hline Diabetes & 1263 & $644(9.5)$ & $619(9.1)$ & 0.46 \\
\hline Bacterial infection & 3327 & $1644(24.3)$ & $1683(24.9)$ & 0.44 \\
\hline Viral infection & 1011 & $526(7.8)$ & $485(7.2)$ & 0.18 \\
\hline Pneumoconiosis & 171 & $90(1.3)$ & $81(1.2)$ & 0.49 \\
\hline
\end{tabular}


Table 2 Incidence rates, hazard ratio, and confidence intervals of TB infection in different stratifications

\begin{tabular}{|c|c|c|c|c|c|c|c|c|}
\hline \multirow[t]{3}{*}{ Variables } & \multirow{2}{*}{\multicolumn{3}{|c|}{$\begin{array}{l}\text { Non-PKD Cohort } \\
n=6770\end{array}$}} & \multirow{2}{*}{\multicolumn{3}{|c|}{$\begin{array}{l}\text { PKD Cohort } \\
n=6770\end{array}$}} & \multicolumn{2}{|l|}{ PKD VS. Non-PKD } \\
\hline & & & & & & & \multirow{2}{*}{$\begin{array}{l}\text { Crude HR } \\
(95 \% \mathrm{Cl})\end{array}$} & \multirow{2}{*}{$\begin{array}{l}\text { Adjusted HR } \\
(95 \% \mathrm{Cl})\end{array}$} \\
\hline & Event & Person years & IR & Event & Person years & IR & & \\
\hline Overall & 114 & 41,183 & 27.68 & 175 & 35,325 & 49.54 & $1.74(1.37-2.20)^{* * *}$ & $1.91(1.51-2.43)^{* * *}$ \\
\hline PTB & 90 & 41,243 & 21.82 & 121 & 35,514 & 34.07 & $1.52(1.16-2.00)^{* *}$ & $1.69(1.29-2.22)^{* *}$ \\
\hline EPTB & 22 & 41,386 & 5.32 & 44 & 35,565 & 12.37 & $2.28(1.37-3.80)^{* *}$ & $2.44(1.46-4.08)^{* * *}$ \\
\hline \multicolumn{9}{|l|}{ Gender } \\
\hline Female & 25 & 18,070 & 13.84 & 46 & 16,280 & 28.25 & $2.00(1.23-3.26)^{* *}$ & $2.22(1.36-3.62)^{* *}$ \\
\hline Male & 89 & 23,114 & 38.51 & 129 & 19,045 & 67.73 & $1.70(1.30-2.23)^{* * *}$ & $1.84(1.4-2.41)^{* * *}$ \\
\hline \multicolumn{9}{|l|}{ Age at baseline } \\
\hline $20-49$ & 5 & 14,842 & 3.37 & 14 & 14,217 & 9.85 & $2.88(1.04-7.99)^{*}$ & $3.29(1.14-9.47)^{*}$ \\
\hline $50-64$ & 21 & 12,306 & 17.06 & 48 & 10,711 & 44.81 & $2.61(1.56-4.36)^{* * *}$ & $2.68(1.6-4.49)^{* * *}$ \\
\hline$>65$ & 88 & 14,035 & 62.70 & 113 & 10,397 & 108.68 & $1.66(1.25-2.19)^{* * *}$ & $1.66(1.25-2.19)^{* * *}$ \\
\hline \multicolumn{9}{|l|}{ Baseline comorbidity } \\
\hline No & 26 & 22,890 & 11.36 & 56 & 20,366 & 27.50 & $2.37(1.49-3.78)^{* *}$ & $2.69(1.69-4.30)^{* * *}$ \\
\hline Yes & 88 & 18,294 & 48.10 & 119 & 14,960 & 79.55 & $1.60(1.22-2.11)^{* * *}$ & $1.71(1.30-2.26)^{* * *}$ \\
\hline Hypertension & 57 & 11,064 & 51.52 & 88 & 9052 & 97.22 & $1.84(1.32-2.56)^{* * *}$ & $1.89(1.35-2.64)^{* * *}$ \\
\hline Hyperlipidemia & 5 & 1918 & 26.07 & 14 & 1500 & 93.35 & $3.56(1.28-9.90)^{*}$ & $4.18(1.46-11.94)^{* *}$ \\
\hline Alcohol related disease & 4 & 422 & 94.81 & 2 & 303 & 66.01 & $0.66(0.12-3.60)$ & $1.52(0.18-13.01)$ \\
\hline Chronic kidney disease & 45 & 6931 & 64.93 & 53 & 5666 & 93.54 & $1.40(0.94-2.08)$ & $1.44(0.97-2.15)$ \\
\hline ESRD & 14 & 3507 & 39.92 & 16 & 3030 & 52.80 & $1.28(0.62-2.62)$ & $1.27(0.61-2.63)$ \\
\hline Chronic liver disease & 20 & 2158 & 92.67 & 18 & 1654 & 108.85 & $1.13(0.60-2.14)$ & $1.25(0.65-2.40)$ \\
\hline COPD & 24 & 1583 & 151.66 & 22 & 1253 & 175.54 & $1.09(0.61-1.94)$ & $1.19(0.66-2.15)$ \\
\hline Diabetes & 15 & 2916 & 51.44 & 25 & 2437 & 102.57 & $1.95(1.03-3.69)^{*}$ & $1.92(1.01-3.66)^{*}$ \\
\hline Bacterial infection & 50 & 7999 & 62.51 & 47 & 6885 & 68.27 & $1.06(0.71-1.58)$ & $1.12(0.75-1.68)$ \\
\hline Viral infection & 15 & 2484 & 60.39 & 22 & 1880 & 117.03 & $1.86(0.96-3.59)$ & $1.82(0.93-3.57)$ \\
\hline Pneumoconiosis & 7 & 222 & 314.69 & 4 & 213 & 187.37 & $0.64(0.19-2.19)$ & $0.69(0.17-2.72)$ \\
\hline
\end{tabular}

IR incidence rates, per 10,000 person-years, $H R$ hazard ratio, $C l$ confidence interval Adjusted HR: adjusted for age, all comorbidities in Cox proportional hazards regression ${ }^{*} p<0.05,{ }^{* *} p<0.01,{ }^{* * *} p<0.001$

incidence curve was plotted using R software. Significance was set at a two-sided $\mathrm{p}$ value of $<0.05$.

\section{Results}

We enrolled 13,540 patients in total (Table 1) with 6770 patients in each cohort. In our cohort, $58 \%$ of the patients were men, and the mean age of the patients was 59.1 years. No significant differences were observed in sex, age, index year, and comorbidities between the groups ( $\mathrm{p} \geq 0.05)$.

Table 2 presents the incidence rates, hazard ratios, and $95 \%$ CIs of TB after stratification. Compared with the non-PKD group, the PKD group displayed a significantly higher risk of TB after adjusting for age, sex, and comorbidities $(\mathrm{aHR}=1.91,95 \% \mathrm{CI}=1.51-2.43)$. When the analysis was classified into pulmonary TB (PTB) and extrapulmonary TB (EPTB), the PKD group exhibited a significantly higher risk of EPTB ( $\mathrm{aHR}=2.44,95 \%$ $\mathrm{CI}=1.46-4.08)$ and also displayed a difference in the risk of PTB when compared with the non-PKD group $(\mathrm{aHR}=1.69,95 \% \mathrm{CI}=1.29-2.22)$. After adjusting for and stratifying by age, sex, and comorbidities, the female $(\mathrm{aHR}=2.22,95 \% \mathrm{CI}=1.36-3.62)$ and male $(\mathrm{aHR}=1.84$, 95\% CI $=1.40-2.41)$ patients; those aged $20-49$ years $(\mathrm{aHR}=3.29, \quad 95 \% \quad \mathrm{CI}=1.14-9.47), \quad 50-64 \quad$ years $(\mathrm{aHR}=2.68, \quad 95 \% \quad \mathrm{CI}=1.60-4.49), \quad$ and $>65 \quad$ years $(\mathrm{aHR}=1.66,95 \% \mathrm{CI}=1.25-2.19)$; and those with any of the comorbidities ( $\mathrm{aHR}=1.71,95 \% \mathrm{CI}=1.30-2.26)$, hypertension $(\mathrm{aHR}=1.89,95 \% \mathrm{CI}=1.35-2.64)$, hyperlipidemia $(\mathrm{aHR}=4.18,95 \% \mathrm{CI}=1.46-11.94)$, and diabetes $(\mathrm{aHR}=1.92,95 \% \mathrm{CI}=1.01-3.66)$ in the PKD cohort had a significantly higher risk of TB than did their counterparts in the non-PKD cohort.

When stratified by the category of with or without comorbidity, the patients with PKD without any comorbidity had a high risk of TB $(\mathrm{aHR}=2.69,95 \% \mathrm{CI}=1.69$ 4.30). When followed within 1 year from the index date, the patients with PKD had a 2.82-fold increased risk 
Table 3 Incidence and hazard ratio of TB infection stratified by the follow-up year

\begin{tabular}{|c|c|c|c|c|c|c|c|c|}
\hline \multirow[t]{3}{*}{ Variables } & \multirow{2}{*}{\multicolumn{3}{|c|}{$\begin{array}{l}\text { Non-PKD Cohort } \\
n=6770\end{array}$}} & \multirow{2}{*}{\multicolumn{3}{|c|}{$\begin{array}{l}\text { PKD Cohort } \\
n=6770\end{array}$}} & \multicolumn{2}{|l|}{ PKD VS. Non-PKD } \\
\hline & & & & & & & \multirow{2}{*}{$\begin{array}{l}\text { Crude HR } \\
(95 \% \mathrm{Cl})\end{array}$} & \multirow{2}{*}{$\begin{array}{l}\text { Adjusted HR } \\
(95 \% \mathrm{Cl})\end{array}$} \\
\hline & Event & Person years & IR & Event & Person years & IR & & \\
\hline \multicolumn{9}{|c|}{ Follow-up year } \\
\hline$<1$ & 26 & 6605 & 39.36 & 67 & 6268 & 106.89 & $2.69(1.71-4.23)^{* * *}$ & $2.82(1.79-4.43)^{* * *}$ \\
\hline $1-3$ & 30 & 11,340 & 26.46 & 47 & 10,261 & 45.81 & $1.73(1.10-2.74)^{*}$ & $1.85(1.17-2.93)^{* *}$ \\
\hline $3-5$ & 24 & 8634 & 27.80 & 27 & 7374 & 36.62 & $1.31(0.76-2.27)$ & $1.50(0.86-2.60)$ \\
\hline$>5$ & 34 & 14,604 & 23.28 & 34 & 11,423 & 29.77 & $1.27(0.79-2.05)$ & $1.54(0.95-2.49)$ \\
\hline
\end{tabular}

IR incidence rates, per 10,000 person-years, $H R$ hazard ratio, $C l$ confidence interval

Adjusted HR: adjusted for sex, age, and all comorbidities in Cox proportional hazards regression

${ }^{*} \mathrm{p}<0.05,{ }^{* *} \mathrm{p}<0.01,{ }^{* * *} \mathrm{p}<0.001$

of $\mathrm{TB} \quad(\mathrm{aHR}=2.82,95 \% \mathrm{CI}=1.79-4.43)$. A 1.85 -fold increased risk of $\mathrm{TB}(\mathrm{aHR}=1.85,95 \% \mathrm{CI}=1.17-2.93)$ was observed in the patients with PKD when followed for 1-3 years after adjusting for demographic factors and comorbidities (Table 3).

\section{Discussion}

TB infection has become a global healthy issue. In 2018, TB had affected 10 million individuals, of whom 1.5 million died, thus imposing a massive burden on the public health system according to the World Health Organization (WHO) [20]. Because of early diagnosis and direct observation of treatment by using anti-tuberculosis agents with advanced public health services in Taiwan, a decreasing trend in TB infection was observed; the case rate decreased from 73 cases per 100,000 population to 36.7 cases per 100,000 population from 2005 to 2019 [21].

We included a large number of patients with PKD and observed them for a long time in our study. Our findings showed a signficantly higher incidence rate of TB in the PKD group (495.4 per 100,000 personyears) than in the non-PKD group (276.8 per 100,000 person-years). In the multivariate analysis after adjusting for confounders, namely sex, age, index year, and comorbidities, the PKD cohort had a 1.91-fold higher risk of TB than did the non-PKD cohort. When stratified by sites involving $\mathrm{TB}$, such as pulmonary (PTB) and extrapulmonary (EPTB) sites, a 3.40-fold higher risk of EPTB was observed in the patients with PKD $(\mathrm{aHR}=2.44,95 \% \mathrm{CI}=1.46-4.08)$. Similarily, a 2.69 fold higher risk of TB was observed in the patients with PKD after excluding any underlying diseases, including diabetes, alcohol consumption, and liver disease, which may contribute to TB infection in the general population. Our findings suggest that PKD is associated with a higher TB infection risk, particularly EPTB infection, which has never been known previously. In addition, our findings may provide indirect evidence implicating PKD underlying abnormal immunological function.

Risk factors for $\mathrm{TB}$ infection can be divided into impaired host immunity and increased exposure. For example, impaired immunity with HIV infection poses a high risk of TB infection, including EPTB or miliary TB infection, and a low CD4 lymphocyte count is a key risk factor for TB relapse [22 23]. Several predisposing factors are associated with TB infection. The risk of TB infection is high in patients with diabetes [24], solid organ transplant [25], renal disease [26], COPD [27], hematologic malignancies [28], diseases under long-term glucocoticoid treatment or tumor necrosis factor treatment [29 30], undernutrition [31], or smoking and alcohol consumption [32 33].

TB is prevalent worldwide, and male patients are particularly prone. Male patients have an approximately twofold increased risk of TB infection [20]. Compared with female patients, more social exposure in male patients accounted for these findings. In the present study, the male patients in the PKD group were associated with an 1.8-fold higher risk of TB infection than did those in the control group, which supports the previous findings. Male sex is supposed to be associated with more rapid progression in PKD1-gene mutant patients with ADPKD [34]. Notably, the observation that female patients with PKD have a 2.2-fold increased risk of TB infection needs to be eluciated further.

Underlying comorbidities in PKD patients can aggravate the risk of TB infection. In this study, we observed that the PKD patients with hypertension $(\mathrm{aHR}=1.89$, 95\% $\mathrm{CI}=1.35-2.64)$, hyperlipidemia $(\mathrm{aHR}=4.18,95 \%$ $\mathrm{CI}=1.46-11.94)$, and diabetes mellitus $(\mathrm{aHR}=1.92$, 95\% $\mathrm{CI}=1.01-3.66)$ had a high risk of TB infection; however, those with alcohol-related disease, chronic kidney disease, chronic liver disease, COPD, diabetes, bacterial infection, viral infection, and pneumoconiosis did not 
have a significantly increased risk of TB infection in the study.

In cases with $\mathrm{TB}$ infection in renal transplantations, more than one-third of the renal transplant patients developed TB infection during the first year post- transplantation [35]. High-dose immunosuppresant agents after the initial renal transplantation might interfere with T-cell function; for example, cyclosporin suppressed purified protein derivative-specific CD4 T-cell reactivity and the production of interleukin-2 and interferongamma [36].

Similarily, patients with PKD in the first year of followup have a high risk of TB, which implies that underlying immunodysregulation may likely contribute to the findings of our study.

\section{Strengths and limitations}

Our data were robust; however, some limitations must be addressed. First, laboratory data could not be obtained from the NHIRD. Some confounders associated with the risk of TB infection, such as tobacco and alcohol consumption, could not be measured. To overcome the inherent potential bias, proxy variables, including COPD incidence for smoking, hypertension, hyperlipidemia, and diabetic incidence for obesity, were included to reduce the bias effect of these confounders.

Second, because universal Bacillus Calmette-Guerin (BCG) vaccination has been offically implemented in Taiwan, EPTB is easily missed in daily practice. Only patients with definitive TB infection were recruited and those with subclinical infections could have been excluded from the study, resulting in the possible underestimation of the results. Third, data of imaging and tissue examinations and details regarding EPTB sites could not be obtained in the study.

\section{Conclusions}

Taken together, our findings suggest that PKD is associated with a 1.91-fold increased risk of TB infection. Medical professionls should maintain a high index of suspicion in daily practice when treating patients with PKD, particularly those with extrapulmonary TB infection.

\footnotetext{
Abbreviations

PKD: Polycystic kidney disease; TB: Tuberculosis; PTB: Pulmonary Tuberculosis: EPTB: Extrapulmonary Tuberculosis; ESRD: End-stage renal disease; PC: Polycystin; NHIRD: National Health Insurance Research Database; LHID: Longitudinal Health Insurance Database; aHR: Adjusted hazard ratio; Cl: Confidence interval; ESRD: End-stage renal disease; ICD-9-CM: International Classification of Diseases, Ninth revision, Clinical Modification.
}

\section{Authors' contributions}

These authors' individual contributions were as follows. Conception/Design: TFC, TMY, CHK; Provision of study material and patients: TFC, TMY; Collection and assembly of data: All authors; Data analysis and interpretation: All authors; Manuscript writing: All authors; Final approval of manuscript: All authors.

\section{Funding}

This study is supported in part by Taiwan Ministry of Health and Welfare Clinical Trial Center (MOHW109-TDU-B-212-114004), China Medical University Hospital (CMU107-ASIA-19, DMR-109-231); MOST Clinical Trial Consortium for Stroke (MOST 108-2321-B-039-003-), Tseng-Lien Lin Foundation, Taichung, Taiwan. The funders had no role in the study design, data collection and analysis, the decision to publish, or preparation of the manuscript. No additional external funding was received for this study.

\section{Availability of data and materials}

The dataset used in this study is held by the Taiwan Ministry of Health and Welfare (MOHW). The Ministry of Health and Welfare must approve our application to access this data. Any researcher interested in accessing this dataset can submit an application form to the Ministry of Health and Welfare requesting access. Please contact the staff of MOHW (Email: stcarolwu@mohw. gov.tw) for further assistance. Taiwan Ministry of Health and Welfare Address: No.488, Sec. 6, Zhongxiao E. Rd., Nangang Dist., Taipei City 115, Taiwan (R.O.C.). Phone: + 886-2-8590-6848. All relevant data are within the paper.

\section{Declarations}

\section{Ethics approval and consent to participate}

The NHIRD encrypts patient personal information to protect privacy and provides researchers with anonymous identification numbers associated with relevant claims information, including sex, date of birth, medical services received, and prescriptions. Therefore, patient consent is not required to access the NHIRD. This study was approved to fulfill the condition for exemption by the Institutional Review Board (IRB) of China Medical University (CMUH104-REC2-115-AR4). The IRB also specifically waived the consent requirement.

\section{Consent for publication}

Yes.

\section{Competing interests}

The authors declare no conflict of interest.

\section{Author details}

'Department of Pediatrics, Taipei City Hospital Zhongxiao Branch, Taipei, Taiwan. ${ }^{2}$ University of Taipei, Taipei, Taiwan. ${ }^{3}$ Department of Education and Research, Taipei City Hospital, Taipei, Taiwan. ${ }^{4}$ Graduate Institute of Biomedical Sciences and School of Medicine, College of Medicine, China Medical University, No. 2, Yuh-Der Road, Taichung 404, Taiwan. ${ }^{5}$ Division of Nephrology, Taichung Veterans General Hospital, Taichung, Taiwan. ${ }^{6}$ Tsaotun Psychiatric Center, Ministry of Health and Welfare, Nantou, Taiwan. ${ }^{7}$ Department of Psychiatry, School of Medicine, National Yang-Ming University, Taipei, Taiwan. ${ }^{8}$ Center for Neuropsychiatric Research, National Health Research Institutes, Zhunan, Taiwan. ${ }^{9}$ University of Texas, Austin, Dell Seton Medical Center, Austin, USA. ${ }^{10}$ Department of Anesthesiology, China Medical University Hospital, Taichung, Taiwan. ${ }^{11}$ Department of Post Baccalaureate Medicine, Kaohsiung Medical University, Kaohsiung, Taiwan. ${ }^{12}$ Department of Nuclear Medicine and PET Center, China Medical University Hospital, Taichung, Taiwan. ${ }^{13}$ Department of Bioinformatics and Medical Engineering, Asia University, Taichung, Taiwan. ${ }^{14}$ Center of Augmented Intelligence in Healthcare, China Medical University Hospital, Taichung, Taiwan.

Received: 29 October 2020 Accepted: 2 June 2021

Published online: 09 June 2021 


\section{References}

1. Dalgaard OZ. Bilateral polycystic disease of the kidneys; a follow-up of two hundred and eighty-four patients and their families. Acta Med Scand Suppl. 1957;328:1-255.

2. Saran R, Robinson B, Abbott KC, et al. US renal data system 2016 annual data report: epidemiology of kidney disease in the United States. Am J Kidney Dis. 2017;69(3 Suppl 1):A7-8.

3. Neumann HP, Jilg C, Bacher J, et al. Epidemiology of autosomal-dominant polycystic kidney disease: an in-depth clinical study for south-western Germany. Nephrol Dial Transplant. 2013;28(6):1472-87.

4. McGovern AP, Jones S, van Vlymen J, Saggar AK, Sandford R, de Lusignan S. Identification of people with autosomal dominant polycystic kidney disease using routine data: a cross sectional study. BMC Nephrol. 2014;15(1):182

5. Willey C, Kamat S, Stellhorn R, Blais J. Analysis of nationwide data to determine the incidence and diagnosed prevalence of autosomal dominant polycystic kidney disease in the USA: 2013-2015. Kidney Dis (Basel). 2019;5(2):107-17.

6. Bergmann C, Guay-Woodford LM, Harris PC, Horie S, Peters DJM, Torres VE. Polycystic kidney disease. Nat Rev Dis Primers. 2018;4(1):50.

7. Cornec-Le Gall E, Audrezet MP, Chen JM, et al. Type of PKD1 mutation influences renal outcome in ADPKD. J Am Soc Nephrol. 2013;24(6):1006-13.

8. Simms RJ. Autosomal dominant polycystic kidney disease. BMJ. 2016:352:1679.

9. Gabow PA. Autosomal dominant polycystic kidney disease. N Engl J Med. 1993:329(5):332-42

10. Rizk D, Chapman AB. Cystic and inherited kidney diseases. Am J Kidney Dis. 2003:42(6):1305-17.

11. Levy $M$, Feingold J. Estimating prevalence in single-gene kidney diseases progressing to renal failure. Kidney Int. 2000;58(3):925-43.

12. Saran R, Robinson B, Abbott KC, et al. US renal data system 2017 annual data report: epidemiology of kidney disease in the United States. Am J Kidney Dis. 2018;71(3 Suppl 1):A7.

13. Gabow PA. Autosomal dominant polycystic kidney disease-more than a renal disease. Am J Kidney Dis. 1990;16(5):403-13.

14. Grantham JJ. Autosomal dominant polycystic kidney disease. N Engl J Med. 2008;359(14):1477-85.

15. Luciano RL, Dahl NK. Extra-renal manifestations of autosomal dominant polycystic kidney disease (ADPKD): considerations for routine screening and management. Nephrol Dial Transplant. 2014;29(2):247-54.

16. Jilg CA, Drendel V, Bacher J, et al. Autosomal dominant polycystic kidney disease: prevalence of renal neoplasias in surgical kidney specimens. Nephron Clin Pract. 2013;123(1-2):13-21.

17. Van Laecke S, Kerre T, Nagler EV, et al. Hereditary polycystic kidney disease is characterized by lymphopenia across all stages of kidney dysfunction: an observational study. Nephrol Dial Transplant. 2018;33(3):489-96.

18. Kunnath-Velayudhan S, Gennaro ML. Immunodiagnosis of tuberculosis: a dynamic view of biomarker discovery. Clin Microbiol Rev. 2011;24(4):792-805

19. Lefford MJ. Transfer of adoptive immunity to tuberculosis in mice. Infect Immun. 1975;11(6):1174-81.
20. World Health Organization-Global tuberculosis report 2019. 2019

21. Lo HY, Chou P, Yang SL, Lee CY, Kuo HS. Trends in tuberculosis in Taiwan, 2002-2008. J Formos Med Assoc. 2011;110(8):501-10.

22. Sonnenberg P, Glynn JR, Fielding K, Murray J, Godfrey-Faussett P, Shearer S. How soon after infection with HIV does the risk of tuberculosis start to increase? A retrospective cohort study in South African gold miners. J Infect Dis. 2005;191(2):150-8.

23. Holmes CB, Wood R, Badri M, et al. CD4 decline and incidence of opportunistic infections in Cape Town, South Africa: implications for prophylaxis and treatment. J Acquir Immune Defic Syndr. 2006;42:464-9.

24. Ayelign B, Negash M, Genetu M, Wondmagegn T, Shibabaw T. Immunological Impacts of Diabetes on the Susceptibility of Mycobacterium tuberculosis. J Immunol Res. 2019;2019:6196532.

25. Clemente WT, Faria LC, Lima SS, et al. Tuberculosis in liver transplant recipients: a single Brazilian center experience. Transplantation. 2009:87(3):397-401.

26. Okada RC, Barry PM, Skarbinski J, Chitnis AS. Epidemiology, detection, and management of tuberculosis among end-stage renal disease patients. Infect Control Hosp Epidemiol. 2018;39(11):1367-74.

27. Inghammar M, Ekbom A, Engstrom G, et al. COPD and the risk of tuberculosis_a population-based cohort study. PLoS ONE. 2010;5(4):e10138.

28. Cheng MP, Abou Chakra CN, Yansouni CP, et al. Risk of active tuberculosis in patients with cancer: a systematic review and meta-analysis. Clin Infect Dis. 2017:64(5):635-44.

29. Jick SS, Lieberman ES, Rahman MU, Choi HK. Glucocorticoid use, other associated factors, and the risk of tuberculosis. Arthritis Rheum. 2006:55(1):19-26.

30. Winthrop K, Baxter R, Liu L, et al. Mycobacterial diseases and antitumour necrosis factor therapy in USA. Ann Rheum Dis. 2013;72(1):37-42.

31. Feleke BE, Feleke TE, Biadglegne F. Nutritional status of tuberculosis patients, a comparative cross-sectional study. BMC Pulm Med. 2019;19(1):182.

32. Bates MN, Khalakdina A, Pai M, Chang L, Lessa F, Smith KR. Risk of tuberculosis from exposure to tobacco smoke: a systematic review and meta-analysis. Arch Intern Med. 2007;167(4):335-42.

33. Lonnroth K, Williams BG, Stadlin S, Jaramillo E, Dye C. Alcohol use as a risk factor for tuberculosis-a systematic review. BMC Public Health. 2008;8:289.

34. Gabow PA, Johnson AM, Kaehny WD, et al. Factors affecting the progression of renal disease in autosomal-dominant polycystic kidney disease. Kidney Int. 1992;41(5):1311-9.

35. Ou SM, Liu CJ, Teng CJ, et al. Impact of pulmonary and extrapulmonary tuberculosis infection in kidney transplantation: a nationwide population-based study in Taiwan. Transpl Infect Dis. 2012;14(5):502-9.

36. Sester U, Wilkens H, van Bentum K, et al. Impaired detection of Mycobacterium tuberculosis immunity in patients using high levels of immunosuppressive drugs. Eur Respir J. 2009;34(3):702-10.

\section{Publisher's Note}

Springer Nature remains neutral with regard to jurisdictional claims in published maps and institutional affiliations.
Ready to submit your research? Choose BMC and benefit from:

- fast, convenient online submission

- thorough peer review by experienced researchers in your field

- rapid publication on acceptance

- support for research data, including large and complex data types

- gold Open Access which fosters wider collaboration and increased citations

- maximum visibility for your research: over 100M website views per year

At BMC, research is always in progress.

Learn more biomedcentral.com/submissions 